\title{
Exploration of Environmental Protection-Oriented Ecoenvironmental Performance Audit System
}

\author{
Jie Wang $\mathbb{D}^{1,2}$ Xiaomei Wang, and $\mathrm{Na} \mathrm{Li}^{2}$ \\ ${ }^{1}$ School of Economics and Management, Nanjing University of Science and Technology, Nanjing 210094, China \\ ${ }^{2}$ School of Economics and Management, Chuzhou University, Chuzhou 239000, China \\ Correspondence should be addressed to Jie Wang; wangjie_nust@163.com
}

Received 13 January 2022; Revised 28 January 2022; Accepted 3 February 2022; Published 25 February 2022

Academic Editor: Thippa Reddy G

Copyright (c) 2022 Jie Wang et al. This is an open access article distributed under the Creative Commons Attribution License, which permits unrestricted use, distribution, and reproduction in any medium, provided the original work is properly cited.

In the era of the COVID-19 (SARS-CoV-2) virus, it has become imperative to audit the environment surrounding us to prioritize public health and the healthcare system. This study aims to accelerate the reform of the economic development modes and the construction of a resource-friendly society. The environmental protection-oriented ecoenvironmental performance audit system is studied here. Based on the current situation of regional ecological pollution in the Yangtze River Economic Belt, the situation and existing problems are analyzed for the ecoenvironment in the Yangtze River Economic Belt from the perspectives of biodiversity, water ecoenvironment, wetland ecoenvironment, and forest ecoenvironment. Then, the situation is deeply analyzed for the ecoenvironmental performance audit project in the Yangtze River Economic Belt. Afterward, we explore the basic characteristics of the environmental audit and summarize the implementation path of resource and environmental audit. The results show that there are some problems in the control and utilization of funds for environmental protection and the development and protection of resources in the cities along the Yangtze River Economic Belt. Then we analyze the problems in the ecoenvironmental performance audit of the Yangtze River Economic Belt and give some suggestions for improving the ecoenvironmental performance audit work. The objective of this paper is to improve the application effect of ecoenvironmental performance audit and provide references for future environmental protection work which will have great impacts on public health and the development of healthcare services.

\section{Introduction}

Recent decades have witnessed the frequent occurrence of global extreme climate, major natural disasters, and global pandemics which seriously affect socioeconomic development, the standard of living and production, and public health. In China, the northeast is prone to drought, while landslides and mudslides are common in the southwest. The resource and environmental problems such as the recent COVID-19 virus bring damage to residents, thereby hindering sustainable socioeconomic development. In this context, ecoenvironmental issues have become the focus of social concern.

The Yangtze River is the largest in China, and the basin area covers about 2.05 million square kilometers, occupying $21 \%$ of the total land area of China $[1,2]$. Meanwhile, the total GDP and population of the Yangtze River Economic Belt exceed $40 \%$ of those in China. The topographic features of the Yangtze River Economic Belt are widely distributed and the ecosystem is diversified. However, due to the barbaric exploitation and loose government supervision in the past, the ecoenvironment system of the Yangtze River Economic Belt has become very vulnerable, with excessive depletion of natural resources and serious soil erosion. Many factors, such as industrial pollution, biodiversity damage, overutilization of mineral resources, over fishery, deforestation, grain for green projects, and uncontrolled groundwater extraction seriously affect the stability of ecological resources in the Yangtze River. Although some progress has been made in biodiversity conservation in the Yangtze River Economic Belt, the habitat and reproduction of some animals and plants have been irreversibly destroyed due to 
human activities which are not conducive to environmental protection. Environmental pollution in the Yangtze River can have an extremely adverse effect on public health and the sustainable economic development of provinces along the Yangtze River Economic Belt. So in this paper, we study the ecoenvironmental performance audit system of the Yangtze River Economic Belt to improve the application effect of environmental audit and therefore provide references for future environmental protection work.

Nowadays, the awareness of ecoenvironmental protection is deepening in China, and the Chinese government has been vigorously promoting environmental protection policies. Meanwhile, advanced data processing and analysis technologies are maturing, and hardware facilities are being improved. Relevant data show that, to protect the ecoenvironment, the state investment in environmental pollution control has increased from 338.7 billion RMB in 2007 to 953.9 billion RMB in 2020 [3]. Besides, many policies are issued to conserve resources and protect the environment, including the construction of an ecoenvironment monitoring network and the construction of the overall framework of big data of ecoenvironment. These policies have enhanced environmental protection and pollution control and promoted the development of the environmental protection industry. In this context, the environmental performance audit has brought great opportunities and challenges. Since the 1980s and 1990s, the Chinese government has carried out audits of special funds for environmental protection. Through decades of rapid development, the environmental audit projects in China have been significantly developed. The successful implementation of large-scale environmental audit projects also provides scientific and effective empirical data for the development of environmental audits in China. However, there are still many problems and deficiencies in the existing environmental performance audit. Based on the case of regional ecological pollution in the Yangtze River Economic Belt, we have analyzed the current situation and existing problems of the ecoenvironment in the Yangtze River Economic Belt were from the aspects of biodiversity, water ecoenvironment, wetland ecoenvironment, and forest ecoenvironment. Then, we have carefully studied the ecoenvironmental protection audit in the Yangtze River Economic Belt which specifically includes the background, the implementation, and the problems of ecoenvironmental performance audit in the Yangtze River Economic Belt. Finally, we put forward some optimization suggestions for improving the audit of the Yangtze River Economic Belt.

The main contribution of our study lies in enriching the research literature of environmental protection, analyzing the key problems in the ecoenvironmental performance audit in China, and putting forward some suggestions for a better environmental protection-oriented ecoenvironmental performance audit system. Nowadays, the ecoenvironmental performance audit is a new audit field in China, and there is no mature empirical model or system. Although some ecoenvironmental performance audits have been carried out in China, most of them are for a certain type of resource, and there is no comprehensive audit for multiple resources.
Therefore, in this paper, the environmental protectionoriented ecoenvironmental performance audit system is studied, theory and practice are combined, the key problems in the current ecoenvironmental performance audit system in China are focused on, and finally, optimization suggestions are proposed.

The remainder of this paper is organized as follows: Section 2 discusses the research method and related literature on environmental audit, Section 3 presents the ecological environment in the Yangtze River Economic Belt, Section 4 analyzes the ecoenvironmental performance audit in the Yangtze River Economic Belt, and we summarize and conclude in Section 5.

\section{Research Method and Related Literature on Environmental Audit}

2.1. Research Method. In this paper, we adopt the methods of literature review, case analysis, and inductive analysis to explore the concept, organization, implementation, technical methods, and application of environmental audit in the context of big data. First, the existing problems are analyzed in the ecoenvironment governance of the Yangtze River Economic Belt through available environment data from relevant yearbooks and literature. Second, the ecoenvironmental protection audit project of the Yangtze River Economic Belt is chosen for case analysis. Third, we analyze the ecoenvironment governance based on the regional environmental monitoring data of the Yangtze River Economic Belt. Finally, we discuss the advantages and disadvantages of environmental audit projects in the Yangtze River Economic Belt in the context of big data, as well as the optimization countermeasures of ecological environmental protection audit in the Yangtze River Economic Belt.

2.2. Related Literature on Environmental Audit. The concept of traditional audit is conservative and the audit methods are backward, which is not conducive to finding audit clues, carrying out relevant work, and implementing follow-up audit rectification. Therefore, the environmental audit should be renovated to adapt to the current situation through theoretical and practical innovation. There is a lot of the latest research on environmental audit. For example, Jiang and Tan (2021) examined the causal relationship between the national environmental audit and regional energy efficiency from the perspective of institutional environment and difference in development level [4]. They found that the implementation of national environmental audit could prominently promote regional energy efficiency, and the external governance effect of national environmental audit on regional energy efficiency is more significant in developed areas and areas with better institutional environments. Through the exploration of the internal mechanism of the national environmental audit affecting regional energy efficiency improvement, the research also found that the national environmental audit can improve regional energy efficiency by promoting technological progress. Nazarova et al. (2020) demonstrated the necessity of an environmental 
auditing system, and they argued that, due to the complexity of the audit objectives and the contradictory and multilevel relationships between its main elements, it is complicated in conducting an environmental audit in the forestry sector. The research emphasized the importance of green economy audit which may be a suitable auditing support mode for forestry enterprises [5]. Marwa et al. (2020) discussed the relationship between environmental disclosure quality and environmental audit. The results showed that the timely disclosure of environmental information was affected by the environmental audit committee, CSR (Corporate Social Responsibility) committee, the auditors, earnings management behavior, firm size, and the industry, while no evidence has been found that there is a statistically significant relationship between CSR committee and the voluntary disclosure of environmental information [6]. Silva et al. (2018) aimed to assess the potential and application of UAVs (Unmanned Aerial Vehicles) in environmental audit and proposed a method for data acquisition and identification of environmental impacts [7]. In conclusion, much literature has attached the importance to environmental audit especially in the era of the COVID-19 (SARS-CoV-2) virus, but unfortunately, so far, few studies have directly explored the environmental protection-oriented ecoenvironmental performance audit in the Yangtze River Economic Belt. Given the importance of the ecological environment in the Yangtze River Basin, we investigate the problem in the ecoenvironmental performance audit of the Yangtze River Economic Belt and give some suggestions for improving audit quality.

\section{Analysis of the Ecological Environment in the Yangtze River Economic Belt}

\subsection{Overview of the Ecological Situation in the Yangtze River Economic Belt}

3.1.1. The Current Situation of Biodiversity in the Yangtze River Economic Belt. In this paper, we chose the Yangtze River Economic Belt as the experimental base. The Yangtze River Economic Belt is a densely populated area with rich biodiversity, and human production activities can have an important impact on the quantity and living conditions of organisms in the area. The daily activities of the surrounding residents will disturb the ecological factors, such as the local soil, atmosphere, and water. Meanwhile, the development of tourism may destruct the habitat and reproduction of plants and animals, resulting in ecosystem imbalance and squeezing the living space of plants and animals $[8,9]$. With the improvement of law enforcement and nature reserves management system, nature reserves throughout China are less subject to human interference, which provides an effective way for the restoration of natural vegetation and the ecosystem. Besides, the implementation of many policies, such as ecological migration and grain for green projects, has effectively protected the habitats of many wild animals and plants. Although some achievements have been made in biodiversity protection, human activities are still interfering with the survival of wild animals and plants. In terms of water pollution, there are about 400,000 chemical enterprises along the Yangtze River Economic Belt, and nearly one-third of the heavily polluted enterprises are distributed within 5 kilometers of the water source, which has seriously destroyed the water environment in the Yangtze River region. Water pollution has also caused serious ecological problems in the Yangtze River, such as the disappearance of the original biological population, a sharp decline in the number of wild animals and plants, and the destruction of biodiversity [10].

3.1.2. Ecological Situation of Water Environment in the Yangtze River Economic Belt. The Yangtze River has a total length of 6,300 kilometers with eight first-class tributaries and many important inner lakes, so water resources in the Yangtze River Basin are quite abundant. However, due to the lack of adequate protection, the water ecological environment in the Yangtze River Economic Belt is not optimistic. The main problems of water ecology are manifested in the following aspects. (1) With the construction of dams, hydropower stations, and other water conservancy facilities, the main Yangtze River and many tributaries are no longer directly connected with the upstream, midstream, or downstream, and many rivers are blocked. (2) Due to the demand for water storage and flood control, the natural fluctuation law in the Yangtze River Basin has been affected, and because of the changes in water temperature, water quantity, and hydrological law in the Yangtze River Basin, the dry season of the Dongting Lake and Poyang Lake in the Yangtze River Economic Belt has advanced, which brings great challenges to the protection of the lake ecology [11]. (3) With the acceleration of urbanization, there are many sand mining sites in the Yangtze River Economic Belt and the speed of sediment exploitation has exceeded the limit of natural recovery in the Yangtze River Basin, which has made the water quality safety and the living space of aquatic animals seriously threatened. Xin et al. (2019) studied a monitoring system to collect real-time information for monitoring water environment information [12].

The water system of the Yangtze River Basin is shown in Figure 1. The Yangtze River, the longest river in China and the third-longest river in the world, originates from Tanggula Mountain in Qinghai Province; it has 49 tributaries, including the Yalong River, Minjiang River, Jialing River, and some other important tributaries shown in Figure 1. Finally, the Yangtze River empties into the East China Sea at Chongming Island in Shanghai.

The comparison of runoff, sediment, and total phosphorus flux in the hydrological control station of the mainstream of the Yangtze River from 2019 to 2020 is shown in Figure 2.

3.1.3. Ecological Situation of Wetlands in the Yangtze River Economic Belt. The wetland resources are abundant in the Yangtze River Basin. The upper reaches of the Yangtze River are dominated by forest wetlands and alpine wetlands, while the middle and lower reaches of the Yangtze River are dominated by freshwater lake wetlands and beach wetlands. The wetland area of the Yangtze River Basin has changed 


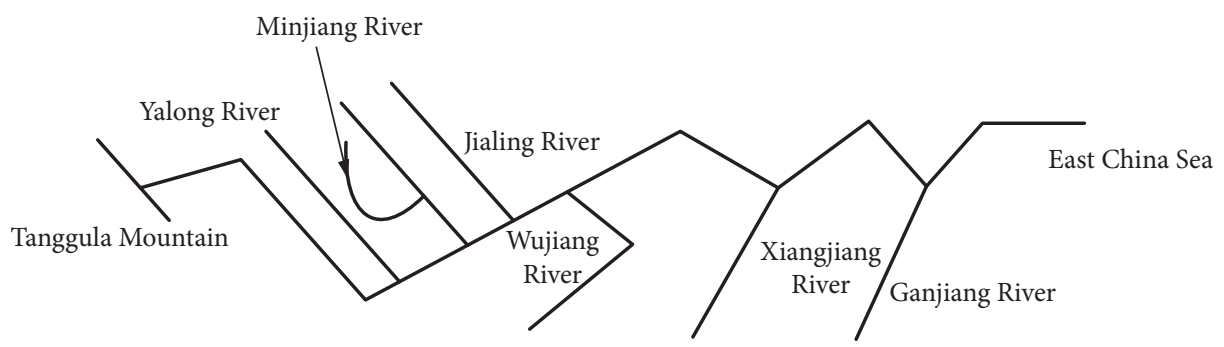

Figure 1: Water system of the Yangtze River Basin.

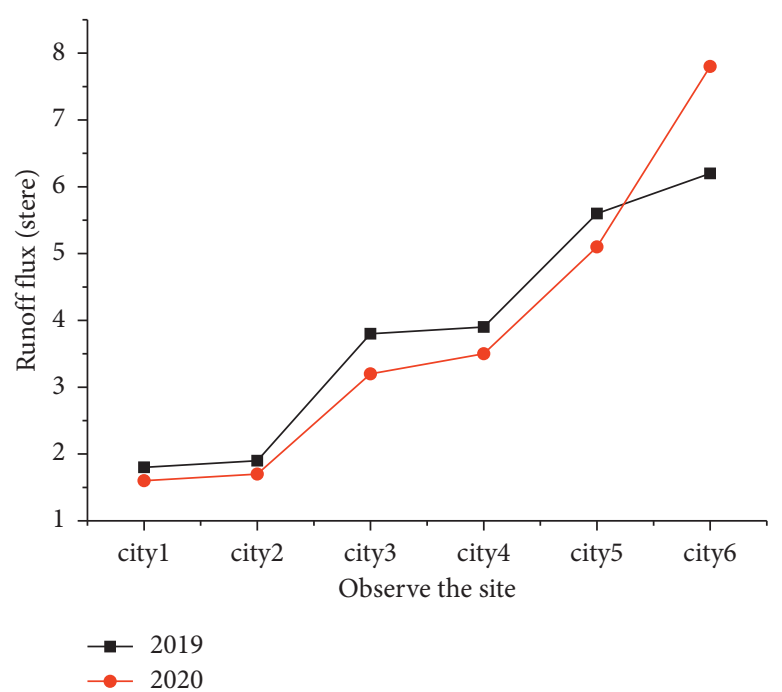

(a)

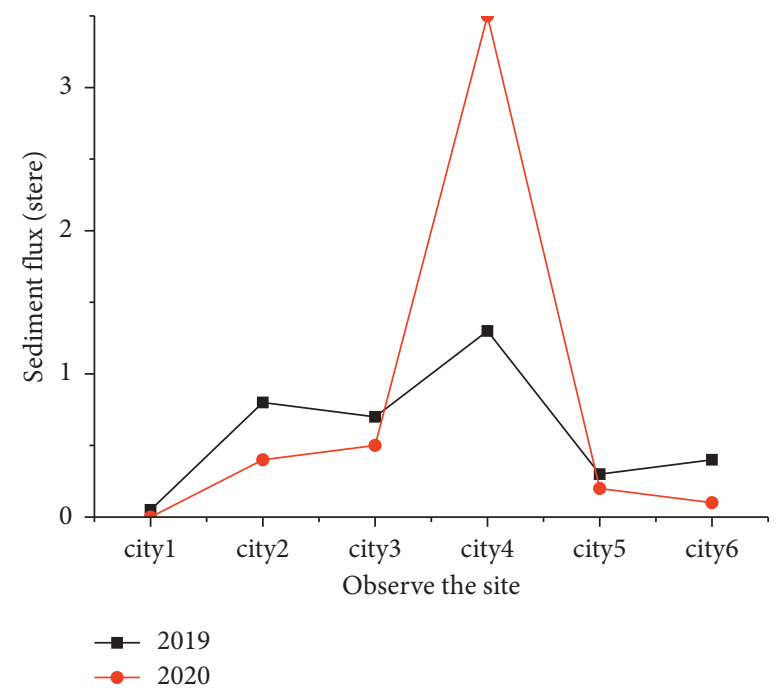

(b)

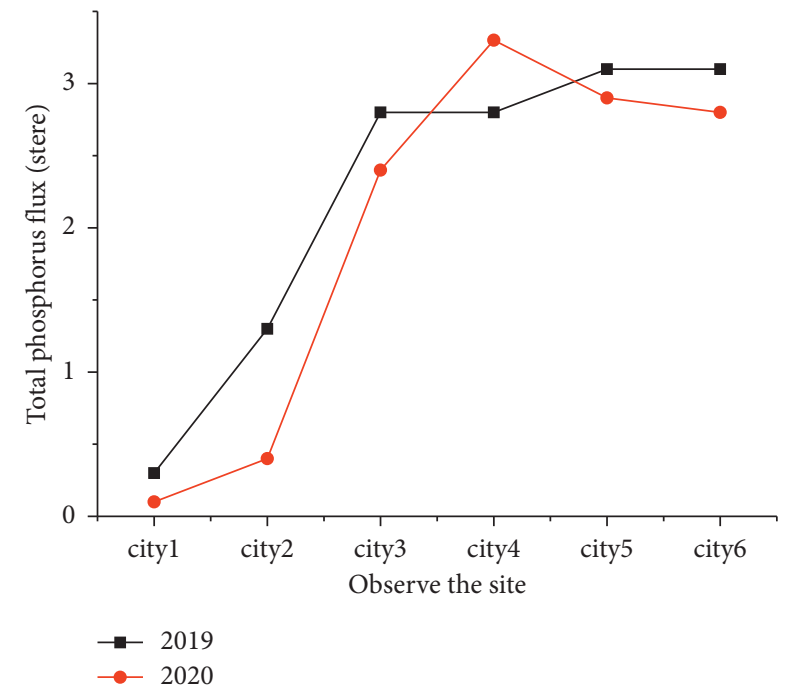

(c)

Figure 2: Runoff, sediment, and total phosphorus fluxes of main urban hydrological stations in the Yangtze River mainstream. (a) Runoff. (b) Sediment. (c) Total phosphorus flux.

greatly. By the year 2000, the lakes in the Yangtze River Basin have decreased significantly, while aquaculture farms have increased significantly, resulting in serious water pollution and eutrophication of the water body. After the year 2000, with the improvement of the environmental protection awareness of the public and the strengthening of national environmental protection governance, the number of lakes has significantly increased, and the wetland ecology has been developing well. LV et al. (2019) studied the space distribution features of BIM (Building Information Modelling) geospatial big data and correspondingly proposed the data store and management model for BIM geospatial big data [13]. 
3.1.4. Ecological Situation of Forest in the Yangtze River Economic Belt. In forest ecology, forestry is crucial to the ecological construction of the Yangtze River Economic Belt and plays an important role in improving the ecosystem. Forest ecology can restore wetland ecosystems, improve the desert ecosystem, build and protect forest ecosystems, and maintain biodiversity. With the construction of key ecological projects, such as desertification control, grain for green projects, construction of protective forest systems in the Yangtze River Basin, and natural forest protection, the forest ecology of the Yangtze River Economic Belt has been significantly improved. The forest coverage rate of the Yangtze River Basin has exceeded 30\%, and the intensity of soil and water loss has decreased by $42 \%$ [14]. Nevertheless, the Yangtze River Economic Belt still faces problems such as uneven distribution of forest resources, insufficient forest volume, and insufficient forest resources per capita. The forest ecoenvironment in the Yangtze River Economic Belt needs to be further improved [15].

Water is essential to human survival, so are land, sunlight, and minerals. Thus, water, land, sunlight, and minerals constitute the natural resource environment. Natural resources are defined as processes that can produce economic benefits under specific conditions. Ecoenvironment refers to the sum of various natural forces that are closely related to human beings and affect human production and life. The composition of natural resources is shown in Figure 3.

\subsection{Analysis of the Yangtze River Wetland Ecosystem and} Existing Problems. The evolution law of the Yangtze River is unique. Different types of wetland ecosystem complexes are evolved through the hydrological process, biogeochemical process, and ecological process. The wetland area of the Yangtze River Basin is 115,400 hectares, including the marsh-wet meadow complex ecosystem and the alpine Canyon River wetland in the upper reaches of the Yangtze River, the river-flood-wetland-Lake Wetland complex ecosystem in the middle reaches of the Yangtze River, and the delta-coastal wetland complex ecosystem in estuaries. As is known to all, the Yangtze River wetland ecosystem has very important ecological, social, and economic benefits. The annual runoff of the Yangtze River is 980 billion cubic meters, accounting for more than 35\% of the total water resources in China. The Yangtze River ensures the livelihood and ecological water resources for the provinces along the Yangtze River basin and supplies water for other provinces, such as Henan, Hebei, and Tianjin. The Yangtze River Basin is located in the subtropical monsoon climate zone with two distinct climates in the rainy season and the dry season. The Yangtze River system and the Yangtze River wetland ecosystem can store floods and reduce the frequency of floods and droughts, and they are important barriers to the ecological security of the basin $[16,17]$. To sum up, the Yangtze River wetland ecosystem is the core capital of the Yangtze River Economic Belt strategy. Figure 4 illustrates the changing trend of ecosystem service value in the Yangtze River Economic Belt, and Figure 5 reveals the changing

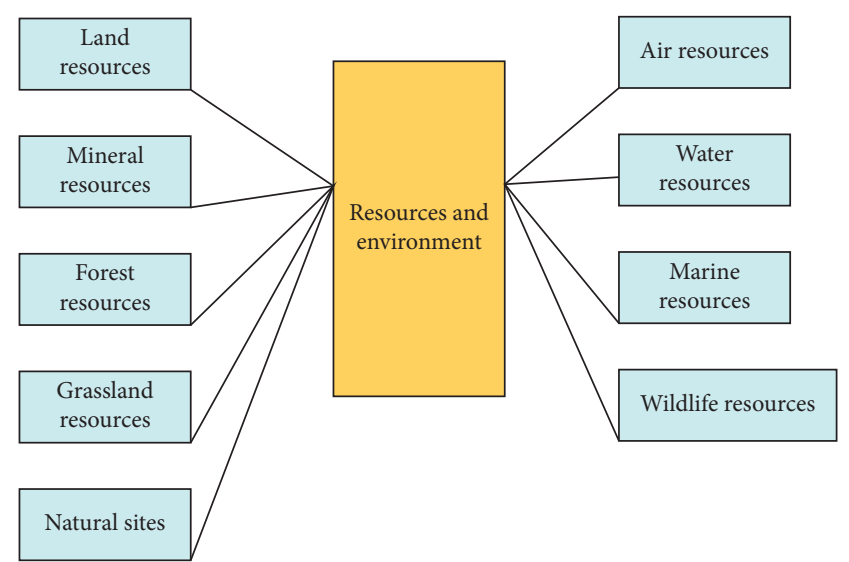

Figure 3: Schematic diagram of natural resources composition.

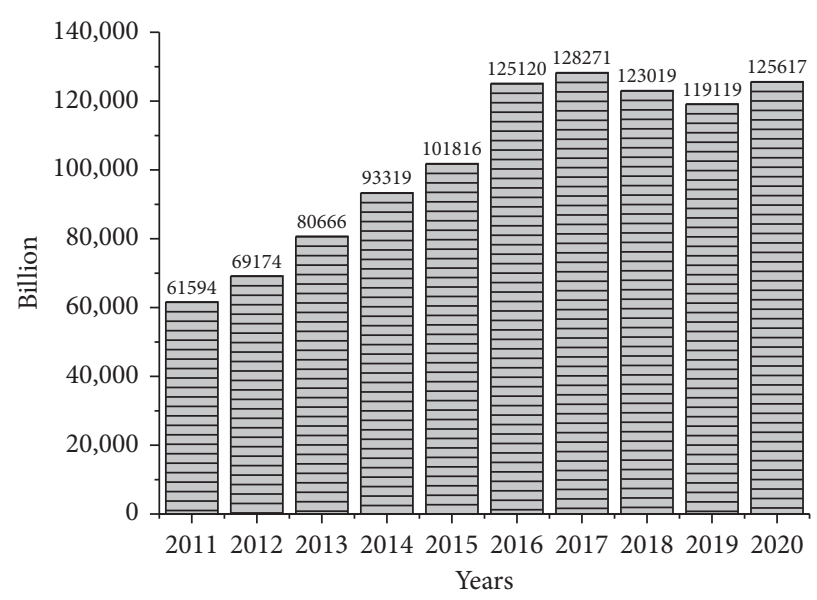

FIGURE 4: Change trend of ecosystem service value in Yangtze River Economic Belt.

trend of ecosystem service value of administrative units in the Yangtze River Economic Belt.

There are three deficiencies in wetland ecological management in the Yangtze River Economic Belt. The first one is multimanagement and piecemeal management, in which the overall interests often give way to local interests, and the interests of the vulnerable groups are deprived by the strong groups. The governance of the Yangtze River Basin still lacks a powerful comprehensive management organization. The second is that wetland protection lacks legislative authority. Currently, China's land law defines a wetland as unused land. Therefore, the wetland has become the victim of the land policy of balance between occupation and compensation, from which a few people get exorbitant profits while violating the interests of the mass [18]. The third is the weak awareness of wetland protection. Most people have not realized the severity of wetland ecosystem degradation in the Yangtze River, and they lack an accurate understanding of the evolution status and future trend of the Yangtze River wetland, which leads to unfriendly ecological protection environment [19]. 


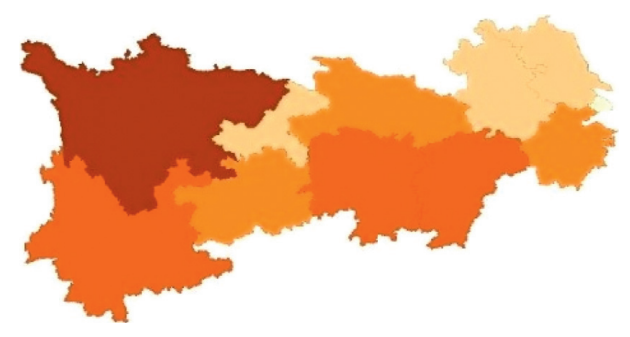

(a)

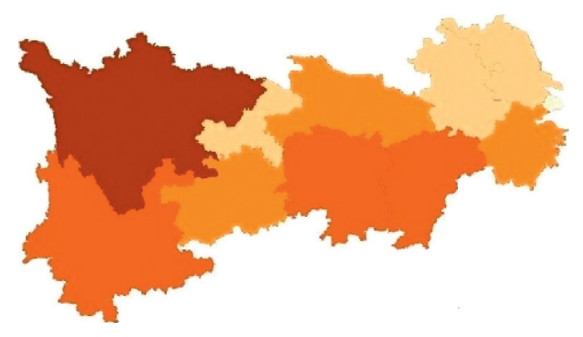

(b)

Figure 5: Changes of ecosystem service value of administrative units in Yangtze River Economic Belt: (a) 2019 and (b) 2020.

3.3. Analysis of the Yangtze River Water Environment Ecosystem and Existing Problems. The Yangtze River basin is a strategic water source in China with its vast territory, diverse internal water environment, and rich biological resources. The Yangtze River bears huge pressure from regional development and plays a key role in ecological security. There are about 300 fish species in the Yangtze River Basin, of which about 170 species are unique to the Yangtze River Basin. Among them, rare birds, such as Siberian Crane and Chinese Merganser, are also widely distributed in the Yangtze River Basin. Additionally, the water environment and ecosystem of the Yangtze River Basin provide shelters for the East Asia-Australia migratory birds. According to the evaluation results of relevant agencies, the Yangtze River Basin occupies 5 of the top 10 in the ranking of 1,031 important wetlands for the complete migration route of migratory birds. However, the current ecological imbalance of the Yangtze River Basin is becoming more and more serious. It is necessary to deeply analyze the outstanding problems in the Yangtze River Basin and take corresponding measures to solve them.

According to relevant research, the problems existing in the ecological governance of the Yangtze River Economic Belt can be summarized into the following three aspects. The first is the improper use of environmental protection funds, which is manifested in the unbalanced use of funds, unreasonable use of funds, or ineffective use of funds. By 2020, a total of 1.3 billion RMB of funds from the comprehensive management of the eight provinces and municipalities along the Yangtze River was deposited into the local financial department, and about 900 million RMB has been deposited into the project authority and related construction units. Additionally, the government and other relevant departments in the eight provinces and municipalities along the Yangtze River illegally used 200 million RMB of ecoenvironmental protection funds to compensate for administrative expenses or project expenditures.

The second problem is the insufficient protection of the ecological environment, which is manifested in the unauthorized provision of water resources, and the lack of oversight on illegal network sales. Data analysis indicates that more than 500 enterprises from different provinces and municipalities along the Yangtze River have sold water resources without permission. More than 50 enterprises have exceeded the water consumption limit. Meanwhile, 600 coastline projects that illegally occupy land from several provinces have not been demolished. Thus, the protection of ecological diversity in many provinces and municipalities has not been implemented at the grassroots level. To obtain a harmonious development with nature, the intensity of further punishment should be increased and real-time systems should be employed.

Third, there are material weaknesses in pollution control. Specifically, the sewage disposed by the sewage treatment plants does not meet the corresponding standards, and the waste disposal in landfill plants does not being carried out effectively. By December 2020, the sewage disposed by many sewage treatment plants in several provinces in the Yangtze River Basin has failed to meet the national Class A discharge standards. The sewage treatment capacity is limited due to the damage to the irrigation and drainage network. In 2020, five provinces and municipalities directly discharged 221 million tons of sewage into the Yangtze River. A total of 45 enterprises in 7 provinces have failed to dispose of the hazardous waste properly, 10 garbage treatment plants in 3 provinces are overloaded, and 5 health care enterprises in 4 provinces failed to dispose of the medical waste according to the regulations.

Figure 6 illustrates the distribution of some chemical parks in the Yangtze River Economic Belt.

\section{Case Analysis of Ecoenvironmental Performance Audit in the Yangtze River Economic Belt}

4.1. The Background of Ecoenvironmental Performance Audit in the Yangtze River Economic Belt. The Yangtze River is the longest in China. The Yangtze River Economic Belt represents the economy zone near the Yangtze River. The Yangtze River Economic Belt covers 11 provinces and municipalities including Guizhou, Yunnan, Sichuan, Chongqing, Hunan, Hubei, Jiangxi, Anhui, Zhejiang, Jiangsu, and Shanghai and covers an area of about 2.05 million square kilometers, with a GDP and population exceeding $40 \%$ of those in China. After decades of development since the reform and opening up, the Yangtze River Economic Belt has become one of the most developed regions in China with a high level of economic development, dense populations, and a complete industrial chain. However, there are many urgent problems with the development of agriculture, industry, and commerce in the Yangtze River Economic Belt, which are mainly the conflicts of interest caused by the inadequate/an imbalance of economic development between regions [20]. The 


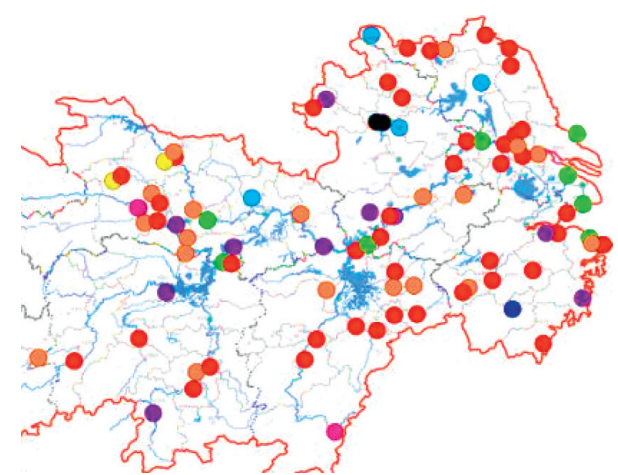

FIGURE 6: Distribution of some chemical parks in the Yangtze River Economic Belt.

political division of the Yangtze River Economic Belt is shown in Figure 7. The basic situation of each province and municipality in 2020 is shown in Figure 8.

In December 2020, the National Audit Office has organized relevant auditors to audit the implementation of policies for ecoenvironmental protection and the use of funds in cities along the Yangtze River Economic Belt and has achieved good audit results. Here, we cite audit results to analyze and summarize audit experience, to provide a reference for the audit work in other regions. The related concepts of ecoenvironmental performance audit are shown in Figure 9. Environmental performance audit is the combination of environmental audit and performance audit. Environmental audit is the process of supervising, authenticating, and evaluating the environment of an organization. Performance audit refers to the audit of the economy, efficiency, and effect of the economic activities of the auditee. Meanwhile, environmental performance audit is an activity in which the audit institution (i.e., the national audit institutions, internal audit institutions, or accounting firms) supervises and evaluates the environmental management system of the auditees as well as the environmental problems and responsibilities arising from economic activities [21].

\subsection{Audit Project Implementation}

4.2.1. Preaudit Investigation Stage. In the preaudit investigation stage, the auditors should determine the scope, objectives, and objects of the audit investigation [22]. The audit objectives can be divided into overall objectives and specific objectives. The overall objective of the ecoenvironmental performance audit is to judge whether the local governments of the provinces along the Yangtze River Economic Belt have implemented the ecological and environmental protection policies by the planning outline. The specific objectives can be separated into two aspects. The first one is to evaluate whether the special funds are used in accordance with regulations and whether there is any surplus or misappropriation. The second one is about resource exploitation and the prevention and control of pollution, which is to evaluate whether resources are overexploited or illegally extracted.

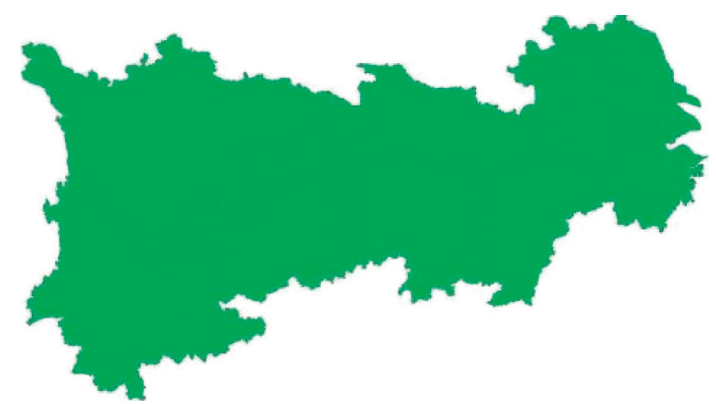

Figure 7: Political division of the Yangtze River Economic Belt.

4.2.2. Audit Method. In the audit process, auditors use the inspection method, inquiry method, letter method, and comprehensive analysis method to obtain reasonable audit evidence to ensure the credibility of audit results. When evaluating the use of special funds, auditors shall inquire the user of funds and the project manager, verify the use of special funds, and check the cash accounts and approval documents of special funds through inspection. Besides, auditors verify the integrity and existence of funds through the letter of confirmation.

4.3. Audit Results. The results of the ecoenvironmental performance audit can be divided into the following three aspects: (1) high-pressure management and use of funds related to ecoenvironmental protection: there are two kinds of problems in this aspect. The first one is that financial departments retain special funds, and the second one is that financial departments do not implement financial support funds. Specifically, by the end of 2020, a total of 1.3 billion $\mathrm{RMB}$ was earmarked for water pollution control in eight cities along the Yangtze Economic Belt, while 200 pollution treatment projects in 10 cities along the Yangtze River Economic Belt have yet to start. (2) Resource development and ecological protection: there are two types of problems in this aspect. The first is that the project density is greater than the bearing standard, and the second is the illegal water intake. By the end of 2020, the provinces and municipalities in the Yangtze River Economic Belt have completed the construction of 250 million small hydropower stations, and the minimum distance between small hydropower stations is only 100 meters, so the construction intensity of small hydropower stations is quite high. In the 10 provinces and municipalities in the Yangtze River Economic Belt, more than 400 enterprises take water without licenses, and more than 100 enterprises take water in excess. The newly built high polluting projects in many provinces and municipalities have not yet gone through the EIA (Environmental Impact Assessment) approval procedures. (3) Pollution control: in terms of pollution control, there are two problems. Firstly, the governance policies are not being carried out effectively, and secondly, the projects are not started in time or do not meet the expected requirements. Specifically, the water quality of the national key lakes which have been under long-term treatment is still very poor, and the centralized sewage treatment equipment has not been established in many development zones. 


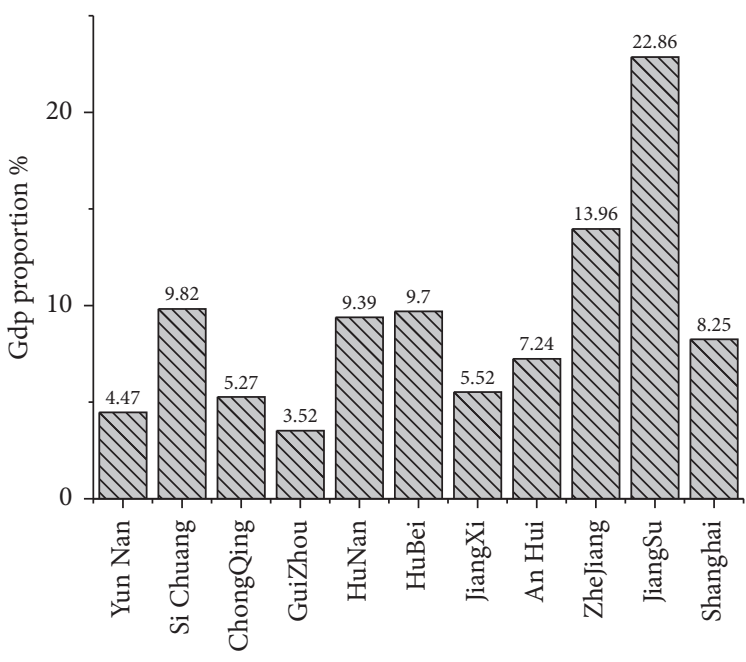

(a)

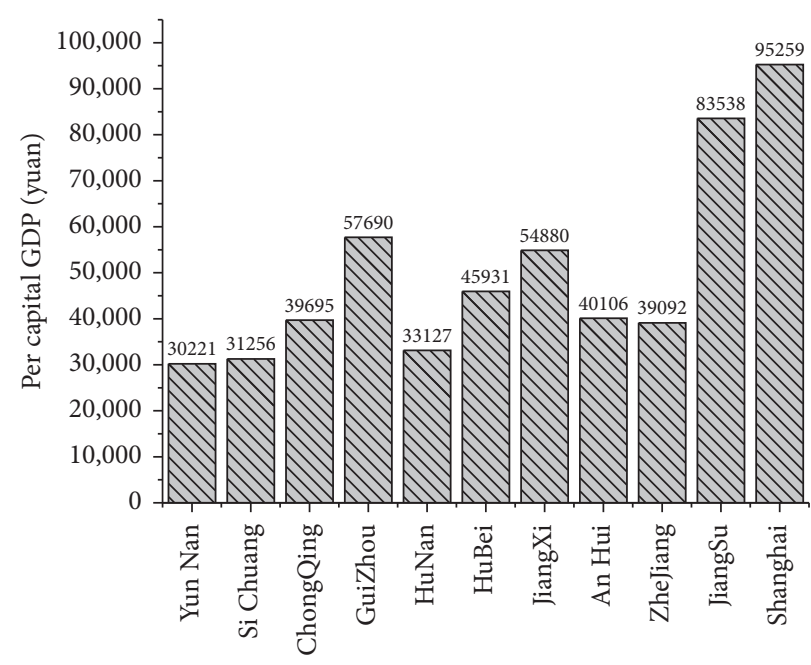

(b)

FIGURE 8: The basic situation of each province and municipality in 2020. (a) GDP proportion and (b) GDP per capital.

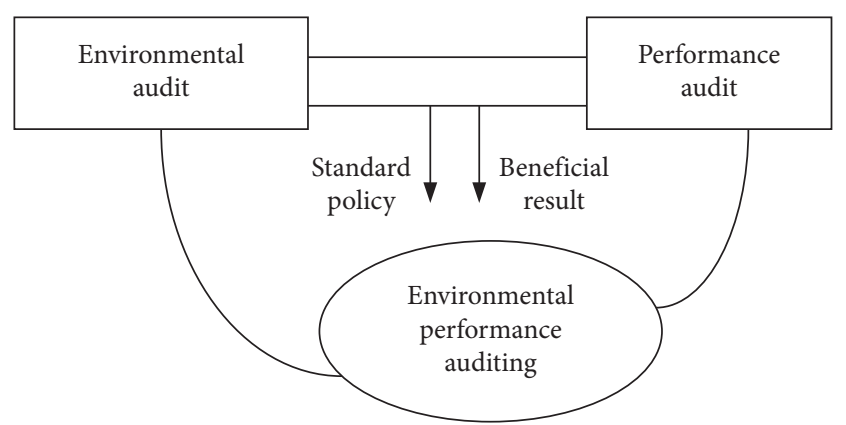

Figure 9: The concept map of ecoenvironmental performance audit.

4.4. Analysis on the Problems of the Ecoenvironmental Performance Audit in the Yangtze River Economic Belt. According to the actual situation in China, environmental performance audit has not formed a relatively well-developed audit mode such as financial audit, and it is still in the initial and exploratory stage. At this stage, there are many problems in the ecoenvironmental performance audit of the Yangtze River Economic Belt which can be summarized as follows. First, the proprietorship of water resources in the River Basin is not clear, and the root of the confusion lies in the lack of clear provisions in the water law. The inconformity of administrative regulations and departmental rules leads to the lack of evaluation criteria in the ecoenvironmental performance audit. Second, the overlapping of government administrative powers leads to the inefficiency of the ecoenvironmental performance audit of the Yangtze River Economic Belt. Nowadays, the management of the Yangtze River Economic Belt mainly adopts a single management mode, which leads to the serious overlapping of functions. As for water resources management, due to the overlapping of functions, all departments try to benefit from the affairs with greater interests, while all departments are unwilling to manage the affairs without interests, which set up so many obstacles to protect the environment of the
Yangtze River Basin and also cause the inefficiency of the audit. Third, the integrity and long-term nature of the environmental pollution problem increased the difficulty of ecoenvironmental performance audit. The problem of water environmental pollution in the Yangtze River Basin is caused by the long-term activities of human beings and cannot be formed and spread in a short time. It is hard to tackle water environmental pollution in a short period due to its complex causes. In the process of water pollution control, different stakeholders have different goals and make different decisions, which makes the environmental standards inconsistent. In this case, it is difficult to solve the pollution problem only by the ecoenvironmental performance audit.

4.5. Optimization Suggestions for Improving the Audit of the Yangtze River Economic Belt. The quantity of natural resources in the Yangtze River Economic Belt is far less than the demand of humans, and the development of administrative regions of the Yangtze River Economic Belt is uneven, provinces in the lower reaches of the Yangtze River Economic Belt have developed better than those in the upper reaches. Due to geographical factors, the provinces in the lower reaches of the Yangtze River Economic Belt can achieve ecoenvironmental protection results in the upper reaches of the Yangtze River Economic Belt at a relatively low cost. With the development of transportation, the possibility of cooperation between cities in different regions of the Yangtze River Economic Belt is increasing. The cooperation between provinces or cities is conducive to the reallocation of resources and the overall progress and development of the basin [23]. The purpose of the ecoenvironmental performance audit is to further promote the improvement of national governance objectives and governance capacity. Therefore, auditors should focus on the development planning of the Yangtze River Basin. During the audit, auditors should strictly review the rationality of 
laws and regulations for the protection of the Yangtze River Basin and evaluate the medium and long-term environmental strategic planning of the Yangtze River Basin, thereby promoting the overall development of the economy, environment, and ecological construction in the Yangtze River Basin. Besides, the auditors should learn to use $3 \mathrm{~S}$ technology to conduct the ecoenvironmental performance audit. The so-called 3S technology, in fact, is remote sensing (RS), geographic information system (GIS), and global satellite positioning system (GPS) collectively. In the ecoenvironmental performance audit of the Yangtze River Economic Belt, auditors can use 3S technology to analyze the area and distribution of the natural resources and make a comparative analysis with the previous year, to evaluate and judge the development and utilization of natural resource assets. The application of $3 \mathrm{~S}$ technology can effectively improve the accuracy of audit results.

\section{Conclusions}

As the government attaches more and more importance to environmental protection, government audit plays an increasingly important role in environmental supervision. Global pandemic situations triggered more and more audit practices to study the ecoenvironmental audit, to improve the ecoenvironmental audit system, and to improve the healthcare system. In this paper, the Yangtze River Economic Belt in the ecoenvironmental protection audit is specifically analyzed using the literature review, case analysis, and inductive analysis from many aspects, such as the audit concept, organization and implementation, technical methods, and result application. Meanwhile, the problems existing in the ecological environmental management of the Yangtze River Economic Belt are analyzed through environmental data, such as the relevant yearbook and literature. The results find that the current audit evaluation system is not perfect, and the reliability of audit results is not high. Consequently, the optimization suggestions are put forward for improving the audit work of the Yangtze River Economic Belt. Our research concludes that auditors should focus on the national environmental protection policies, strictly implement environmental performance audit procedures, and learn to use advanced technologies to conduct the ecoenvironmental performance audit to improve the quality of ecoenvironmental performance audit. However, there are still some deficiencies in this paper. During the audit analysis, we only conducted the environmental performance audit on water resources, while audit on other resources has not been performed. In the future work, with the development of environmental audit technology, audit on other environmental pollution problems such as carbon emission will be further improved.

\section{Data Availability}

The data used to support the findings of this study are available from the corresponding author upon request.

\section{Conflicts of Interest}

The authors declare that there are no conflicts of interest regarding the publication of this paper.

\section{Acknowledgments}

The work was supported by the 2017 general project of Humanities and Social Sciences Research in Universities in Anhui Province (project number: SK2017B05); the 2017 major project of Humanities and Social Sciences Research in Universities in Anhui Province (project number: SK2017A0417); the 2019 project of Chuzhou University (project number: RJZ01); the 2021 project of Scientific Research and Practice Innovation for Postgraduate in Jiangsu Province (project number: KYCX21_0391).

\section{References}

[1] Y. Pan, Z. Liu, and Y. Wang, "Research on pricing of renewable water resources in supply chain environment," IOP Conference Series: Materials Science and Engineering, vol. 612, no. 5, Article ID 052023, 2019.

[2] M. N. Chisola, M. v. der Laan, and K. L. Bristow, "A landscape hydrology approach to inform sustainable water resource management under a changing environment. A case study for the Kaleya River Catchment, Zambia," Journal of Hydrology: Regional Studies, vol. 32, no. 1, Article ID 100762, 2020.

[3] L. Meng, W. Wang, T. Li, C. Liao, L. Zhao, and Y. Chen, "Evaluation of the effects of shear stress on crucian carps passing through turbines," IOP Conference Series: Earth and Environmental Science, vol. 774, no. 1, Article ID 012147, 2021.

[4] Q. Jiang and Q. Tan, "National environmental audit and improvement of regional energy efficiency from the perspective of institution and development differences," Energy, vol. 217, Article ID 119337, 2021.

[5] K. Nazarova, V. Hotsuliak, V. Miniailo, M. Nezhyva, and V. Mysiuk, "Accounting, analysis and environmental audit as an imperative of the development of green economy in the state's economic security system," E3S Web of Conferences, vol. 166, Article ID 13003, 2020.

[6] M. Marwa, B. Salhi, and A. Jarboui, "Environmental audit and environmental disclosure quality," Scientific Annals of Economics and Business, vol. 67, no. 1, pp. 93-115, 2020.

[7] C. A. Silva, C. R. Duarte, J. A. B. Sabadia, and M. V. S. Souto, "Drone in the environmental audit: potentialities and applications," Anuário do Instituto de Geociências - UFRJ, vol. 41, no. 3, pp. 207-215, 2018.

[8] F. Morante-Carballo, N. Montalván-Burbano, P. CarriónMero, and K. Jácome-Francis, "Worldwide research analysis on natural zeolites as environmental remediation materials," Sustainability, vol. 13, no. 11, p. 6378, 2021.

[9] K. Wu and M. Tian, "Research on environment education strategy water resource utilization based on dynamics," Journal of Coastal Research, vol. 115, no. sp1, p. 498, 2020.

[10] M. Polemio and K. Walraevens, "Recent research results on groundwater resources and saltwater intrusion in a changing environment," Water, vol. 11, no. 6, p. 1118, 2019.

[11] V. Mikhailov, N. Kudrevatykh, and T. Tyuleneva, "The research of environmental-and-economic risks of the coal mining enterprise impact on water resources," E3S Web of Conferences, vol. 134, no. 2, Article ID 01019, 2019.

[12] W. Xin, T. Can, W. Wei, and L. Ji, "Change detection of water resources via remote sensing: an L-V-nsct approach," Applied Sciences, vol. 9, no. 6, pp. 1223-1235, 2019.

[13] Z. Lv, X. Li, and H. Lv, "BIM big data storage in WebVRGIS," IEEE Transactions on Industrial Informatics, vol. 16, no. 99, p. 1, 2019. 
[14] L. Kong, H. Zheng, E. Rao, Y. Xiao, Z. Ouyang, and C. Li, "Evaluating indirect and direct effects of eco-restoration policy on soil conservation service in Yangtze River Basin," The Science of the Total Environment, vol. 631-632, pp. 887894, 2018.

[15] F. Zhang, Z. Zhang, R. Kong et al., "Changes in forest net primary productivity in the Yangtze River basin and its relationship with climate change and human activities," Remote Sensing, vol. 11, no. 12, p. 1451, 2019.

[16] S. Lu, X. Tang, X. Guan, F. Qin, X. Liu, and D. Zhang, "The assessment of forest ecological security and its determining indicators: a case study of the Yangtze River Economic Belt in China," Journal of Environmental Management, vol. 258, Article ID 110048, 2020.

[17] D. Zhang, X. Wang, L. Qu et al., "Land use/cover predictions incorporating ecological security for the Yangtze River Delta region, China," Ecological Indicators, vol. 119, Article ID 106841, 2020.

[18] M. Silver, M. Barosky, and C. Aviles, "Water audit expands reuse opportunities at the brewery," World Water: Water Reuse \& Desalination, vol. 8, no. 4, pp. 21-23, 2017.

[19] X. Li, X. Yu, L. Jiang, W. Li, Y. Liu, and X. Hou, "How important are the wetlands in the middle-lower Yangtze River region: an ecosystem service valuation approach," Ecosystem Services, vol. 10, pp. 54-60, 2014.

[20] A. V. Glushchenko, I. F. Gorlov, N. V. Filipov, D. A. Mosolova, E. P. Kucherova, and N. I. Mosolova, "Internal ecological audit of environmental facilities of agricultural enterprises," IOP Conference Series: Earth and Environmental Science, vol. 677, no. 3, Article ID 032047, 2021.

[21] R. Huang and Y. Li, "Undesirable input-output two-phase DEA model in an environmental performance audit," Mathematical and Computer Modelling, vol. 58, no. 5-6, pp. 971-979, 2013.

[22] S. Aslam, R. U. Rehman, and M. Asad, "Linking environmental management practices to environmental performance: the interactive role of environmental audit," Pakistan Journal of Commerce and Social Sciences (PJCSS), vol. 14, no. 1, pp. 99-119, 2020.

[23] S. Fu, H. Zhuo, H. Song, J. Wang, and L. Ren, "Examination of a coupling coordination relationship between urbanization and the eco-environment: a case study in Qingdao, China," Environmental Science and Pollution Research, vol. 27, no. 19, pp. 23981-23993, 2020. 